\title{
Locomotion Evoked by Stimulation of the Brain Stem in the Atlantic Stingray, Dasyatis sabina
}

\author{
Christine A. Livingstona and Robert B. Leonard \\ University of Texas Medical Branch, Marine Biomedical Institute, Galveston, Texas 77550
}

\begin{abstract}
The primary pathway descending to the spinal cord to initiate locomotion in the stingray is located in the intermediate to ventral portion of the lateral funiculus; a second pathway is located in the dorsolateral funiculus. The goal of this study was to identify the origins of these pathways in the rhombencephalic reticular formation (RF). To do this we used microstimulation of the RF in conjunction with selective lesions of the brain stem and spinal cord. In some animals microinjections of excitatory amino acids were used to avoid stimulating axons of passage. Locomotion in the contralateral pectoral fin was evoked by microstimulation of the dorsal and ventral reticular nuclei, the middle and superior RF, and the ventral portion of the lateral RF. The regions from which locomotion was evoked by chemical stimulation were more restricted and included the rostral dorsal reticular nucleus, the middle RF, and the adjacent ventral lateral RF. This area encompasses the magnocellular RF and coincides with the distribution of numerous reticulospinal cells that project ipsilaterally into the ventral half of the lateral funiculus. Our results indicate, then, that locomotion in the stingray is mediated primarily by a pathway originating in the magnocellular RF that descends ipsilaterally in the ventral half of the lateral funiculus to elicit swimming in the contralateral pectoral fin. We suggest that this primary pathway is specifically associated with the control of locomotion. We also demonstrated that locomotion can be evoked independently from the lateral RF, but is probably mediated by an indirect pathway relaying near the spinomedullary junction or in the rostral spinal cord.
\end{abstract}

Vertebrate locomotion is generated by neuronal circuitry located within the spinal cord (Grillner, 1981). In those species studied to date, locomotion can be evoked by stimulation of the midbrain (Shik et al., 1966; Kashin et al., 1974, 1981; Leonard et al., 1979; Johnels and Steg, 1982; Coles et al., 1983; Droge and Leonard, 1983a, b; Ross and Sinnamon, 1984). However, this midbrain locomotor region (MLR) does not project directly to the spinal cord (Garcia-Rill et al., 1983; Steeves and Jordan, 1984), indicating that there is a group of relay neurons, most

\footnotetext{
Received Apr. 4, 1989; revised July 17, 1989; accepted July 24, 1989.

This work was supported by USPHS Research Grant NS 11255. C.A.L. was supported by USPHS Training Grant NS 07185. We thank Lonnell Simmons for secretarial assistance, Hanna Atkins for editing, and Todd Cunnington for photography. C.A.L. also acknowledges the support and advice of Dr. Albert J. Berger, and Dis. Marc C. Binder and John D. Steeves for critical review of the manuscript.

Correspondence should be addressed to Dr. Christine A. Livingston, Department of Physiology \& Biophysics, SJ-40, School of Medicine, University of Washington, Seattle, WA 98195.

a Present address: Department of Physiology \& Biophysics (SJ-40), University of Washington School of Medicine, Seattle, WA 98195.

Copyright (C) 1990 Society for Neuruscience 0270-6474/90/010194-11\$02.00/0
}

likely reticulospinal cells, located in the caudal brain stem (Orlovsky, $1970 \mathrm{a}, \mathrm{b}$ ). Initial studies of locomotor control in the caudal brain stem focused on a discrete area in the lateral reticular formation (RF), termed the pontine locomotor strip (PLS) (Mori et al., 1977; Shik and Yagodnitsyn, 1977). Although locomotion can be evoked from the PLS, neurons within this structure do not project directly into the ventrolateral funiculus of the spinal cord (Shik and Yagodnitsyn, 1978; Kazennikov et al., 1979, 1984; Armstrong, 1986), which is known to be the locus of the descending pathway for the initiation of locomotion (Stccves and Jordan, 1980; Eidclbcrg ct al., 1981a, b; Williams et al., 1984; Sholomenko and Steeves, 1987).

More recent studies in cats and birds, attempting to localize the origin of the primary locomotor pathway, have implicated the magnocellular and gigantocellular fields of the medial pontomedullary RF (Orlovsky, 1970a, b; Mori et al., 1978; Selionov and Shik, 1981; Shimamura and Kogure, 1983; Zemlan et al., 1983; Shefchyk et al., 1984; Steeves and Jordan, 1984; Steeves et al., 1987; Noga et al., 1988). This area of the RF was first implicated by the finding that stimulation here facilitated MLRevoked locomotion in cats (Mori et al., 1978). Shefchyk and coworkers (1984) demonstrated that locomotion evoked from the MLR was dependent on the medial pontomedullary RF and that locomotion evoked by stimulation of sites medial to the MLR was dependent on the PLS. Subsequent anatomical studies verified that the MLR does project into the magnocellular/gigantocellular RF and that neurons just medial to the MLR project to the PLS (Steeves and Jordan, 1984). Later it was shown that locomotion can be elicited by stimulation of the magnoand gigantocellular reticular fields in cats, rats, and birds (Ross and Sinnamon, 1984; Steeves et al., 1987; Noga et al., 1988). These results are consistent with observations that the magnocellular RF is the predominant source of reticulospinal fibers in the ventral spinal cord (Kuypers and Maisky, 1977; Tohyama et al., 1979), and that the primary pathway for initiating locomotion descends in the ventral funiculi (Steeves and Jordan, 1980; Eidelberg et al., 1981a, b; Williams et al., 1984).

As an alternative to studying locomotion in preparations in which the motor pattern is as complex as that in cats or as simple as that in lampreys, Leonard and colleagues developed the Atlantic stingray, Dasyatis sabina, as a model for vertebrate locomotion (Coggeshall et al., 1978; Leonard et al., 1979; Williams et al., 1981; Droge and Leonard, 1983a, b). Previously in the stingray, we identified the ventral half of the lateral funiculus as the locus of the primary pathway for the initiation of locomotion; a second pathway was identified in the dorsolateral funiculus (DLF) (Williams et al., 1984). Previous work in which discrete injections of HRP were made into these funiculi revealed that the reticulospinal pathways descending in the ventral half of the lateral funiculus originate largely from the dorsal 
reticular nucleus and the middle $\mathrm{RF}$ of the caudal brain stem, including the gigantocellular RF (Livingston, 1987). The reticulospinal pathways descending in the DLF originate from the ventral reticular nucleus and the lateral RF of the caudal brain stem. In the present study, we applied electrical and chemical stimulation to the brain stem in conjunction with lesions of the CNS to define those regions in the caudal brain stem from which locomotion can be evoked. We determined which of these regions encompass the origins of the locomotor pathways to the spinal cord. To localize the regions from which swimming was mediated due to stimulation of the cells of origin of the locomotor pathways, we used microinjections of the excitatory amino acid glutamate (Behbehani and Fields, 1979; Goodchild et al., 1982). Although we expected to identify distinct medial and lateral regions from which locomotion could be evoked, the locomotor region in the brain stem of the stingray consisted of a continuous region that encompassed the dorsal reticular nucleus, portions of the ventral reticular nucleus, the middle and superior RF, and the ventral portion of the lateral RF.

Preliminary results of this study have been presented elsewhere (Livingston and Leonard, 1986).

\section{Materials and Methods}

General procedures. Stingrays $(n=29)$ were anesthetized by immersion in tricaine methanesulfonate (Finquel, Ayerst Labs, $60 \mathrm{mg} /$ liter artificial seawater). The brain was exposed from the spinomedullary junction to the caudal boundary of the telencephalon. The animals were anemically decerebrated (Droge and Leonard, 1983a) and the ccrcbcllum removed. The brain was transected at the caudal boundary of the midbrain. Occasionally an additional transection was placed in the rostral rhombencephalon to prevent spontaneous locomotion. In 16 of the 29 animals, 3-10 segments of the rostral spinal cord also were exposed to allow lesioning of the dorsolateral and/or ventral quadrants during the experiments.

Swimming was recorded with bipolar EMG electrodes inserted into the superficial elevator and depressor muscles of 1 myotome (recording sites E1 and D1); a third electrode was placed in the elevator muscle 10-15 segments caudal to the first pair of electrodes (recording site E2) (Lennard et al., 1979; Williams et al., 1984). Three electrodes were similarly placed in the contralateral pectoral fin. Electromyographic activity during swimming was recorded for later analysis.

The brain stem was stimulated with a monopolar stainless steel electrode. Short trains of cathodal pulses $(100 \mu \mathrm{sec}, 30-70 \mathrm{~Hz}, 4-100 \mu \mathrm{A})$ were delivered at increments of $250 \mu \mathrm{m}$ within each track. The brain was systematically stimulated along electrode tracks arranged in a grid pattern. The grid extended from about 1-2 mm caudal to the brain transection to $1-2 \mathrm{~mm}$ caudal to the obex. The electrode tracks were separated by $0.5-2.0 \mathrm{~mm}$. Within each track the location and electrical threshold at each site from which swimming could be evoked were noted. Swimming evoked by suprathreshold stimulation at the site with the lowest threshold in each track was recorded on FM tape. One or two sites in alternate planes were marked electrolytically $(25 \mu \mathrm{A}, 25 \mathrm{sec})$ and were visualized subsequently by the Prussian blue technique.

In 7 animals, a dual electrode was used for electrical and chemical stimulation. A steel stimulating electrode was glued to the shank of a glass microelectrode and was bent so that the tips of each were within $200 \mu \mathrm{m}$ of one another. This dual electrode was attached to a $10-\mu 1$ Hamilton syringe filled with an excitatory amino acid solution. The brain was tracked as described above using electrical stimulation to identify the site in each track with the lowest threshold for evoking locomotion. At this site, $0.1-5.0 \mu$ lof homocysteic acid $(0.1 \mathrm{M}, 1$ animal), D-glutamic acid $(0.01 \mathrm{M}, 1$ animal), or L-glutamic acid $(0.01 \mathrm{M}, 5$ animals $)$ were pressure-injected at a rate of $1.0 \mu \mathrm{l} / \mathrm{min}$. All amino acids were dissolved in elasmobranch Ringer's solution and adjusted to a $\mathrm{pH}$ of 7.0-7.6. The chemicals were slowly injected (up to a volume of $5.0 \mu \mathrm{l}$ ) until swimming was elicited. If no locomotion was elicited in response to $5 \mu \mathrm{l}$ of the amino acid solution, the site was considered nonresponsive to chemical stimulation. In each experiment an equivalent injection of the Ringer's solution adjusted to the same $\mathrm{pH}$ was injected at another chemically responsive site to verify that the response was not mediated artifactually. To estimate the spread of the amino acids, an equivalent volume of Fast green $(10 \% \mathrm{w} / \mathrm{v})$ was injected into the opposite side of the brain. The maximal spread of Fast green detectable was determined during subsequent histological processing. Typically, chemical stimulation was attempted at a maximum of $8-12$ sites per animal to minimize tissue damage due to the chemical infusions.

At the end of each experiment, the animals were perfused transcardially with $10 \%$ formalin containing $1-2 \%$ potassium ferrocyanide. The brains were removed, post-fixed, and sectioned transversely (thickness, $40 \mu \mathrm{m}$ ). Wet sections, with sites marked electrolytically or with Fast green injections, were sketched immediately. The electrode tracks were reconstructed from these sections after histological processing. Spinal cord tissue containing lesions was post-fixed, serially sectioned $(15 \mu \mathrm{m})$, stained (Klüver and Barrera, 1953), and examined to verify the extent of the spinal lesion.

Experimental paradigms. To define the area of the brain stem from which locomotion could be evoked by microstimulation, a complete grid of tracks was made through the rhombencephalon of 5 animals.

To locate those areas from which locomotion was mediated by stimulation of neurons or their dendrites rather than axons of passage, we determined the distribution of sites from which locomotion could be evoked chemically in 7 animals.

To determine whether locomotion evoked from either the medial or lateral RF was mediated via direct reticulospinal projections into either the dorsolateral or ventral half of the lateral funiculus, the brain stem was stimulated before and after lesioning of these areas of the spinal cord in 13 animals. Because the reticulospinal pathways project to the spinal cord predominantly ipsilaterally (Livingston, 1987; C. A. Livingston, T. C. Ritchie, B. J. Williams, and R. B. Leonard, unpublished observations), the spinal lesions were always placed ipsilateral to the side of the brain stem to be stimulated. In 6 of 13 animals after the second stimulation series, another lesion that was complementary to the first dorsal or ventral quadrant lesion was placed 1-2 segments caudally. The cumulative lesions, if located in the same segment, would have constituted a hemisection of the spinal cord. Another series of tracks was made through the brain stem. In 2 of these animals, a hemisection of the spinal cord was placed caudal to the first 2 lesions, and several more tracks were made through the brain stem.

To determine whether the locomotor sites in the lateral brain stem were effective when isolated from the medial RF, a longitudinal lesion extending from the dorsal to the ventral surface of the brain stem was placed between the medial and lateral RF in 4 animals. The lesion extended from $\sim 1 \mathrm{~mm}$ caudal to the obex, $\sim 10-15 \mathrm{~mm}$ rostrally through the superior RF. The lesions were made with a microscalpel or as a series of electrolytic lesions. The location and completeness of these lesions were subsequently verified histologically. Anatomical evidence in cats suggests that the lateral RF projects into the medial RF over rostrocaudal distances of 1-2 mm (Garcia-Rill, 1986). Therefore, stimulation sites were always located at least $2 \mathrm{~mm}$ from the rostral and caudal ends of the lesions. In 3 of these experiments after identification of effective locomotor sites in the lateral RF, the DLF of spinal segment 2 was lesioned also to determine whether locomotion evoked from these sites was mediated by the DLF.

Data analysis. Cross-sections of the rhombencephalon were sketched at $1-2-\mathrm{mm}$ intervals. The electrode tracks were reconstructed from the histological sections, and the thresholds for evoking locomotion at effective sites were plotted on the drawings. Sites at which chemical stimulation was effective or ineffective were noted.

FM tape records of electromyographic swimming activity were analyzed off-line. Swimming recorded in several preparations was analyzed as described previously (Droge and Leonard, 1983b; Williams et al., 1984) to determine whether the timing characteristics of evoked swimming were significantly altered. In 1 experiment, spontaneous swimming was recorded in a decerebrated stingray. Swimming evoked subsequently in this animal by stimulation of the brain stem was compared with spontaneous swimming to determine whether the 2 were similar.

Anatomical definitions and terminology used in this report are based on those of Smeets et al. (1983).

\section{Results}

Swimming evoked by microstimulation of the brain stem

In 28 of 29 animals, microstimulation of the brain stem typically elicited swimming only in the contralateral pectoral fin (Fig. 1). Movement of the electrode across the midline resulted in a 
Figure 1. Locomotion evoked by electrical stimulation of the rhombencephalon. $A-C$, Representative sections of the brain stem from the rostrocaudal levels indicated in $F$. Shaded area represents those areas of the brain stem in 1 animal from which locomotion could be evoked by stimulation at 4-30 $\mu \mathrm{A}$. $D$, Swimming recorded as EMG activity from the pectoral fins during stimulation $(20 \mu \mathrm{A}, 40 \mathrm{~Hz})$ at the site marked by the $X$ in $B$. The alternation of activity recorded at sites c.E1 and c.Dl and the phase lag in activity recorded at sites c.E2 relative to c.E1 are characteristic of swimming behavior in the stingray. Rhythmic locomotion was observed only in the fin contralateral (c) to the site of stimulation. No activity was evoked in the ipsilateral fin $(i) . E$, Single section from the brain of another animal illustrating the graduation in the thresholds for evoking locomotion within the effective locomotor areas. The thresholds at each site $(40 \mathrm{~Hz}, 100$ $\mu \mathrm{sec}$ pulses) were $1-5 \mu \mathrm{A}\left(X^{\prime} \mathrm{s}\right), 6-10 \mu \mathrm{A}$ (filled circles), or 11-30 $\mu \mathrm{A}$ (open circles). $F$, Schematic drawing of the dorsal view of the brain illustrating the rostrocaudal levels of the sections shown in $A-C$ and $E . C C$, cerebellar crest; $I O$, inferior olivary nucleus; $I R d$, dorsal reticular nucleus; $I R v$, ventral reticular nucleus; $L R F$, lateral reticular formation; $M L F$, medial longitudinal fasciculus; $M R F$, middle reticular formation; $n V I I$, facial nucleus; $n X m$, dorsal motor nucleus of the vagus; $P L L$, posterior lateral line lobe; $V L$, vagal lobe.
A

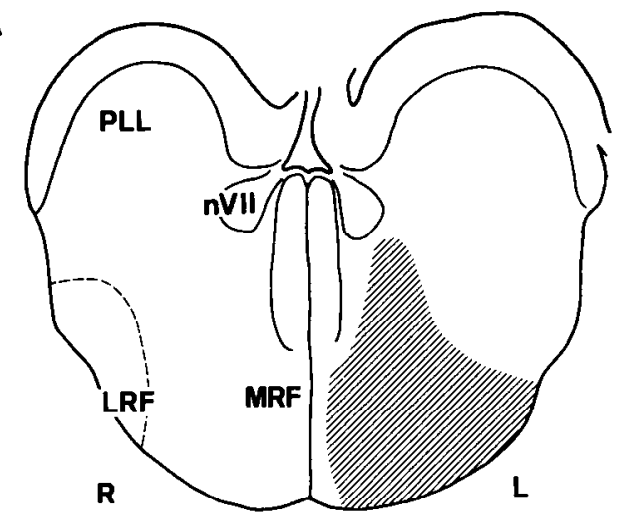

B

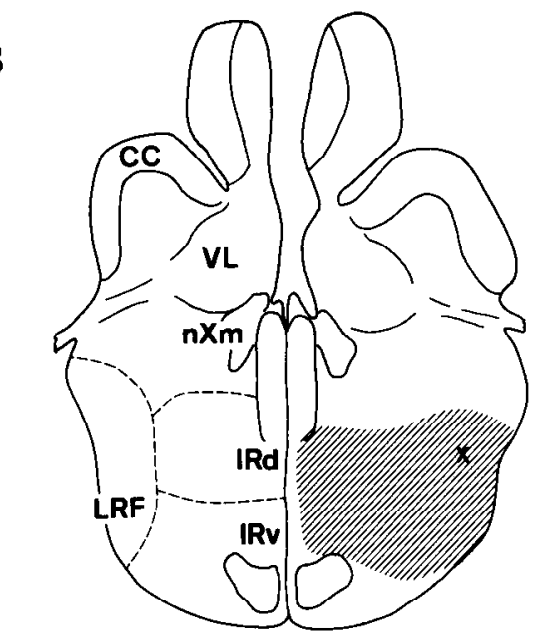

C

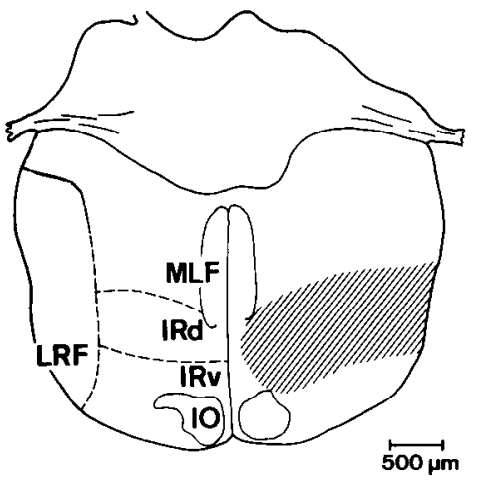

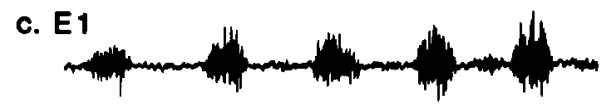

C. D1

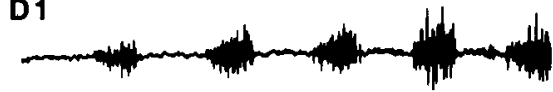

c. E2

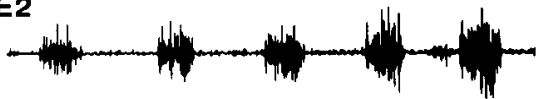

i. E1

i. D1

i. E2
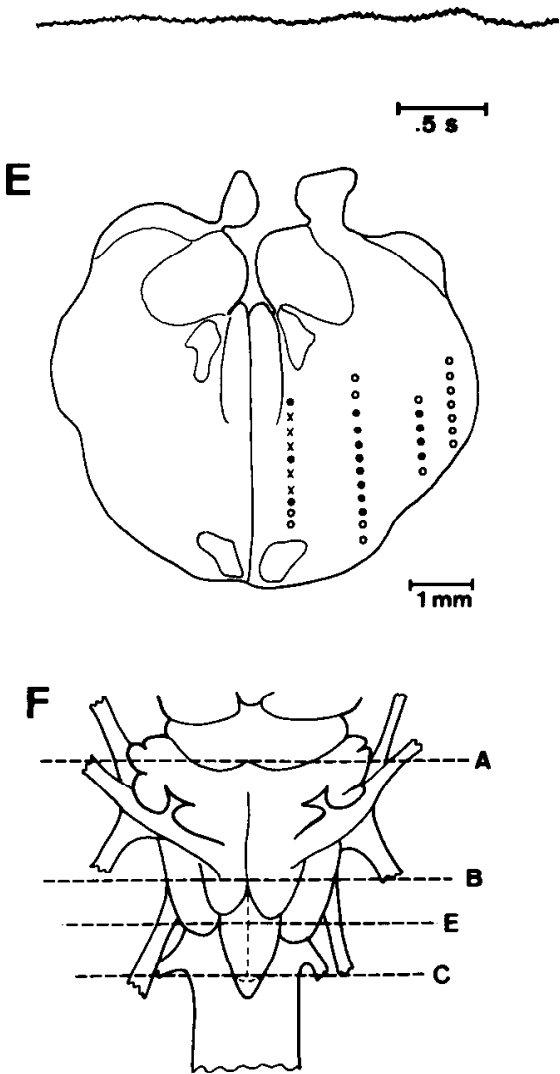

distinct switch from swimming evoked in 1 fin to swimming in the opposite fin. Locomotion was not elicited by stimulation at the midline, but could be elicited $\sim 200 \mu \mathrm{m}$ from the midline. In all animals, a few isolated sites were found from which bilateral swimming was evoked, usually at high stimulation intensities. A consistent pattern in the distribution of these sites was not discernible. Stimulation of sites outside of the locomotor regions (Fig. 1) evoked various responses, such as tonic elevation or depression of the fins, nonswimming movements of the fins, tail movements, eye movements, or alterations in respiratory rate.

During normal swimming in the intact stingray, a metachronal wave progresses from the rostral to caudal portion of the enlarged pectoral fins. In the EMG records of brain-stem-evoked swimming, such alternating activity in the elevator and depressor muscles of a single segment (E1 vs D1) and phase lags in the activity recorded at E2 relative to E1 were evident (Fig. $1 D)$. The timing characteristics of such unilateral brain-stemevoked swimming were quantitatively similar to those observed for swimming in intact or decerebrate stingrays (Droge and Leonard, 1983b). In 1 experiment where the timing characteristics of spontaneous swimming in the intact animal were compared with those of brain-stem-evoked swimming, no significant differences were found in the phase coupling, burst durations, or segmental timing delays measured from the EMG records.

The locomotor area of the brain stem defined by microstimulation at intensities of $<50 \mu \mathrm{A}$ extended from near the midline to the ventral lateral edge of the tegmentum at all levels of the rhombencephalon (Fig. 1). Effective areas included the dorsal and ventral reticular nuclei of the inferior $R F$, the middle and superior RF, and the ventral part of the lateral RF (Fig. 1, $A-$ $C)$. In the caudal medulla, the effective area in the lateral RF 

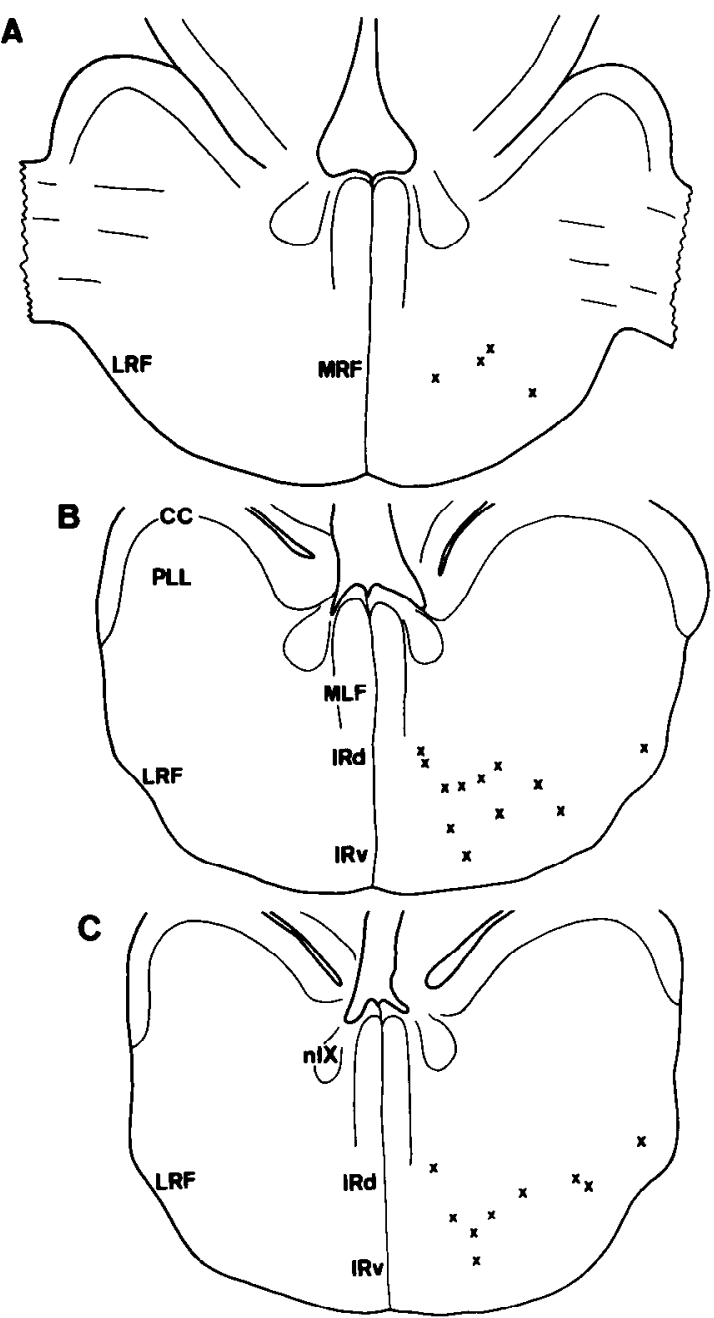
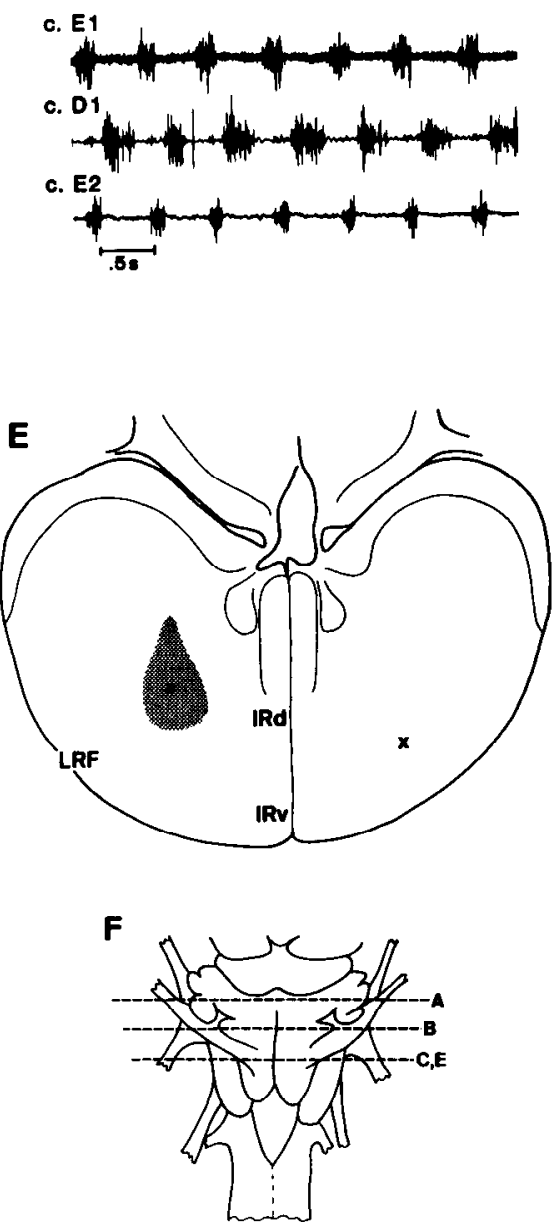

Figure 2. Locomotion evoked by $\mathrm{mi}$ croinjections of GLU into the brain stem. $A-C$, Representative cross-sections of the brain stem taken from the rostrocaudal levels indicated in $F$. $X$ 's mark all sites from which locomotion could be evoked in 7 animals. $D$, EMG recordings of locomotion evoked in the contralateral pectoral fin by injection of $0.6 \mu \mathrm{l}$ of GLU at the site marked by the $X$ in $E . E$. Spread of a $0.6-\mu$ l injection of Fast green at the site marked by the filled circle is represented by the shaded area. $F$, Schematic drawing of the dorsal view of the brain stem illustrating the rostrocaudal levels of the sections in $A-C$ and $E$ was larger and sometimes extended into the dorsolateral tegmentum. Rostrally, in the middle and superior RF, the effective area frequently extended to the ventromedial edge of the brain stem.

Typically, the sites with the lowest electrical thresholds (defined at $40 \mathrm{~Hz}, 100 \mu \mathrm{sec}$ pulses) were also the sites from which the most natural and vigorous swimming could be evoked with the shortest latency to response. Therefore, these sites were defined as the most effective sites. The most effective sites were centered in the dorsal reticular nucleus, the middle RF, and the ventral lateral RF (Fig. $1 F$ ). Thresholds in the ventral lateral RF were often, but not consistently, slightly elevated. Vigorous swimming could be evoked from the dorsal reticular nucleus and ventral lateral RF with thresholds of 4-10 $\mu \mathrm{A}$. The thresholds for eliciting locomotion from the ventral reticular nucleus usually were $10-30 \mu \mathrm{A}$ higher than those in the dorsal reticular nucleus. These results suggest that the locomotor region of the caudal brain stem is centered within the dorsal reticular nucleus.

Evoked swimming was typically vigorous and did not require additional stimulation of other CNS sites or exteroceptive stimulation. Swimming continued as long as brain stem electrical stimulation was maintained. The latency from the onset of stimulation was variable; typically it was $1-5$ sec. Swimming ceased immediately or within several seconds after stimulation ceased. The latency to responsc was inverscly corrclated with the in- tensity of stimulation. The speed and vigor of swimming were directly correlated with stimulation intensity and frequency. A similar relationship between stimulation intensity and the speed or mode of locomotion was reported in birds (Steeves et al., 1987). Excessively high stimulation intensities (4-7 times threshold) resulted in a breakdown in the organization of rhythmic activity and led to "thrashing" behavior.

\section{Swimming evoked by chemical stimulation of the brain stem}

In 7 animals, locomotion was evoked by pressure injection of D-homocysteic acid $(0.1 \mathrm{M})$, D-glutamic acid $(0.01 \mathrm{M})$, or L-glutamic acid $(0.01 \mathrm{M})$ into the brain stem. Swimming recorded in the contralateral fin after an injection of L-glutamate (GLU) is illustrated in Figure $2 D$. At sites from which locomotion could be evoked by chemical stimulation, infusion volumes of 0.1 $1.6 \mu \mathrm{l}$ of GLU were usually effective. Locomotion evoked by microinjections of GLU occurred as a single continuous episode of swimming. Swimming evoked by a single injection of L-glutamate lasted, in some cases, for $<30 \mathrm{sec}$, and in others, for $\sim 3$ min. The vigor and speed of swimming usually were greatest during the first 5-20 sec of the response and gradually decreased until the swimming stopped.

Swimming could be evoked chemically from the rostral portion of the dorsal reticular nucleus (the gigantocellular RF) and the middle and the adjacent lateral RF (Fig. $2, A-C$ ). The lo- 


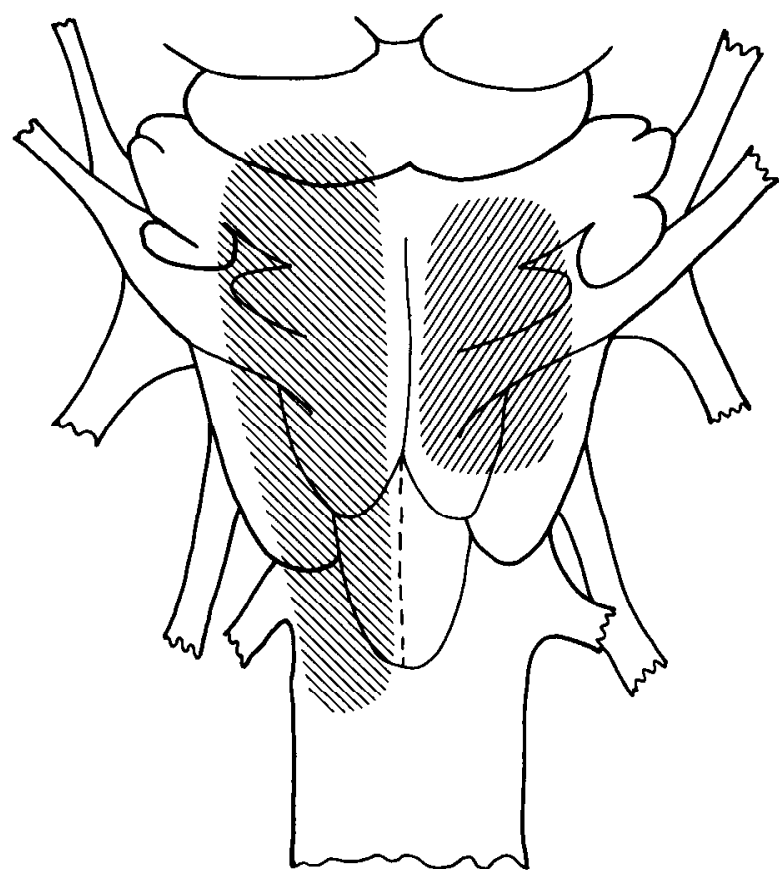

Figure 3. Schematic drawing of the dorsal view of the brain stem illustrating, on the left, the rostrocaudal extent of the areas from which locomotion was evoked by electrical stimulation, and on the right, the rostrocaudal extent of the areas from which locomotion was evoked by chemical stimulation.

comotor region of the brain stem that was defined chemically was distinctly restricted rostrocaudally relative to the area that was defined electrically (Fig. 3). Sites in the caudal rhombencephalon were consistently nonresponsive to microinjection of amino acids. These results indicate that the cells of origin of the descending locomotor pathways are located in the gigantocellular reticular fields of the mid-rhombencephalon.

\section{Effects of spinal cord and brain stem lesions on evoked locomotion}

Lesions of the reticulospinal pathways on one side of the spinal cord impaired locomotion (in the contralateral fin) evoked by stimulation of the brain stem ipsilateral to the lesion.

Lesions of the dorsolateral funiculus. Lesions of the DLF had no effect on the distribution of sites from which locomotion could be elicited. Locomotion was elicited from equivalent areas on the right and left sides of the brain stem after lesioning of the right DLF in 2 animals (Fig. 4A). The thresholds for eliciting locomotion at these sites were unaltered and the vigor of evoked swimming was normal.

Lesions of the ventral quadrant. Interruption of the ventral quadrant of the spinal cord either abolished or seriously impaired brain-stem-evoked locomotion in the contralateral fin. The effectiveness of stimulation in the medial and lateral RF was impaired equally by these lesions. In the experiment illustrated in Figure $4 B$, the left ventral quadrant was lesioned. The distribution of effective sites on the right side of the brain was normal. However, stimulation at intensities of 2.5-10 times threshold on the left side of the brain failed to evoke locomotion. Similar effects were observed at other levels of the rhombencephalon.

In 1 of 3 animals in which the ventral quadrant was lesioned, locomotion clicited from the brain stem ipsilateral to this lesion was completely abolished. In the other 2 animals a few isolated effective sites were found in the medial and lateral RF. The thresholds at these sites were 2-8 times higher than those at equivalent sites on the contralateral side of the brain. In 2 other experiments, the ventral quadrant lesions were incomplete; in these cases, only weak swimming could be evoked from very restricted areas. In summary, lesions of the ventral quadrant of the spinal cord either abolished locomotion evoked from the brain stem or dramatically reduced the number of effective sites, increased the threshold at these sites, and/or decreased the vigor of swimming elicited.

Cumulative lesions of the spinal cord. In 6 experiments, we determined whether locomotion evoked from the few sites that remained effective after transection of the ventral quadrant of the spinal cord might be mediated by reticulospinal fibers located in the dorsal half of the lateral funiculus. Lesions of the dorsal and ventral quadrants, separated by 1-2 segments, were placed successively in the spinal cord. Consistent with the results presented above, lesions of the dorsal quadrant had no further effect on the distribution of effective locomotor sites still present in the brain stem after ventral quadrant lesions. These results indicated that evoked swimming can be mediated by indirect pathways that do not require exclusively either the dorsal or the ventral half of the ipsilateral lateral funiculus.

In 2 experiments, the first 2 lesions were followed by a hemisection on the same side of the spinal cord. Hemisection of the spinal cord abolished evoked swimming in 1 of these animals, but in the second, effective sites were found from which weak locomotion could be elicited at high stimulation intensities.

Effects of brain stem lesions on evoked locomotion. To determine whether the locomotor regions of the medial and lateral RF were distinct from one another, we separated the medial and lateral RF in 4 animals by a longitudinal lesion extending from $\sim 1 \mathrm{~mm}$ caudal to the obex through the superior RF. Subsequently, swimming was evoked from sites both medial and lateral to the lesion (Fig. 5A). After such lesions, swimming evoked from these sites required a higher stimulation intensity and was usually less vigorous. However, identification of these sites indicated that the medial and lateral RF must each represent the origin of a pathway capable of independently initiating locomotion.

Reticulospinal cells located in the lateral RF project predominantly into the DLF (Livingston, 1987). To determine whether, after isolation from the medial RF, locomotion evoked from the lateral RF was mediated via direct spinal projections, lesions of the DLF were placed in the rostral spinal cord of 3 animals with lesions of the brain stem. In 2 of these 3 animals, effective sites were found in the lateral brain stem after lesioning of the DLF(Fig. 5, $B-D$ ). Therefore, swimming evoked from the lateral RF independent of the medial RF is not mediated by direct reticulospinal projections into the DLF.

\section{Discussion}

Swimming evoked by microstimulation or by microinjections of excitatory amino acids into the brain stem

The primary goal of this work was to identify the origins of the reticulospinal pathways underlying locomotion. To do this we used the combined techniques of microstimulation and microinjection of excitatory amino acids into the brain stem. Electrical microstimulation applied at low current intensities allowed us to repeatedly stimulate discrete foci of neural tissue. We cstimated the spread of current in our cxpcriments to have 


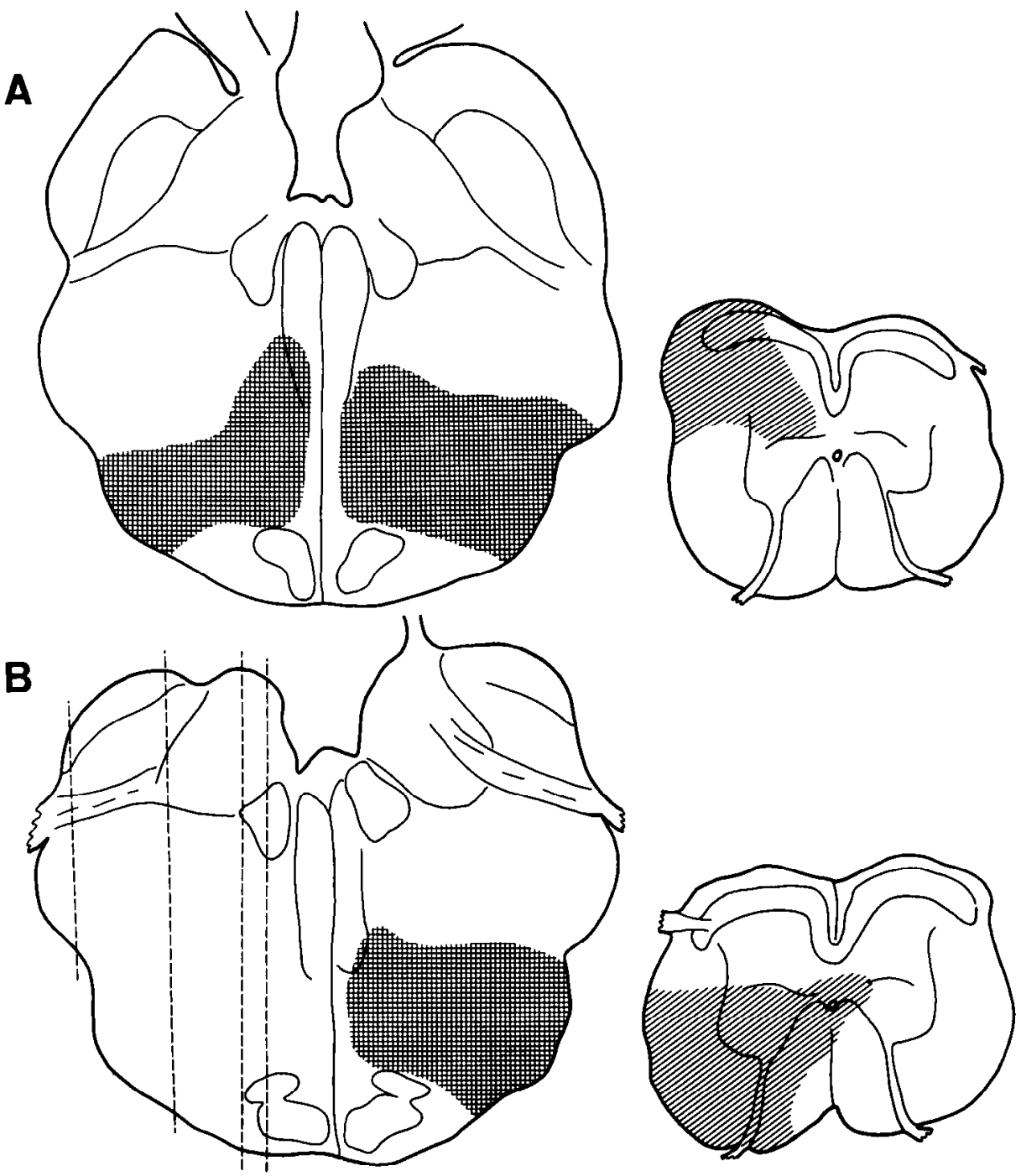

Figure 4. Effect of lesioning the spinal cord on the regions from which locomotion can be evoked. $A$, right, Position of a lesion in the left dorsal quadrant of the spinal cord. Left, Regions from which locomotion could be evoked from the right and left sides of the brain after lesioning the spinal cord. $B$, right, Lesion of the left ventral quadrant in the spinal cord. Left, Those areas from which locomotion could be evoked $(<40 \mu \mathrm{A}, 40 \mathrm{~Hz})$ on the right side of the brain after lesioning of the spinal cord. I ocomotion could not be evoked on the left side of the brain by stimulation at $>100 \mu \mathrm{A}$ along the electrode tracks illustrated by dotted lines.

been from as little as $0.125 \mathrm{~mm}$ at $25 \mu \mathrm{A}$ to $0.5 \mathrm{~mm}$ at $100 \mu \mathrm{A}$ (Wise, 1972; Ranck, 1975; Bagshaw and Evans, 1976). These estimates are supported by the rapid rise in thresholds that we observed when tracking over distances of $0.5-1.0 \mathrm{~mm}$.

Microinjections of excitatory amino acids to stimulate focused sites in the CNS eliminated the possibility of stimulating axuns of passage (Behbehani and Fields, 1979; Goodchild et al., 1982), thus localizing more accurately the cells of origin of the reticulospinal pathways underlying locomotion. However, the possibility of adverse effects on the brain tissue during repeated injections limited the use of this technique in those experiments requiring stimulation of many sites. Also, it is difficult to define the extent of the chemical spread. Based on the results of equivalent injections of Fast green, we are confident that in our experiments there was minimal spread of the amino acids. Further, injections of relatively large volumes $(5 \mu \mathrm{l})$ of GLU at $1 \mathrm{~mm}$ from a site responsive to $\langle 1 \mu \mathrm{l}$ did not evoke locomotion. The rapid onset and the short duration of swimming responses following injections were similar to those described previously (Goodchild et al., 1982; Garcia-Rill and Skinner, 1987) and indicate that our stimulation sites were discretely focused.

Locomotion could be evoked by microstimulation from both the medial and lateral rhombencephalic RF, from the spino- medullary junction through the superior RF. However, the distribution of sites from which locomotion could be evoked in response to chemical stimulation is more restricted rostrocaudally than that of sites responsive to electrical stimulation (Fig. 3). Areas responsive to microstimulation extended through the dorsal and ventral nuclei of the inferior RF, the middle and superior RF, and the ventral portion of the lateral RF; sites responsive to excitatory amino acids extended only from the rostral third of the inferior RF (primarily the dorsal reticular nucleus) through the middle RF, encompassing the gigantocellular RF. This suggests that descending pathways underlying locomotion originate from cells within these nuclei. Locomotion evoked by microstimulation rostral and caudal to these nuclei most likely was mediated by stimulation of axons afferent or efferent to the gigantocellular RF.

Swimming evoked by stimulation of the brain stem was elicited in the contralateral pectoral fin in all but 1 of the 29 animals studied. This is consistent with previous experiments in which electrical microstimulation and lesioning of the spinal cord revealed that the primary locomotor pathway descends in the ventral half of the lateral funiculus (Williams et al., 1984) to evoke swimming in the contralateral pectoral fin. Discrete injections of HRP into this funiculus resulted in retrogradely la- 
A

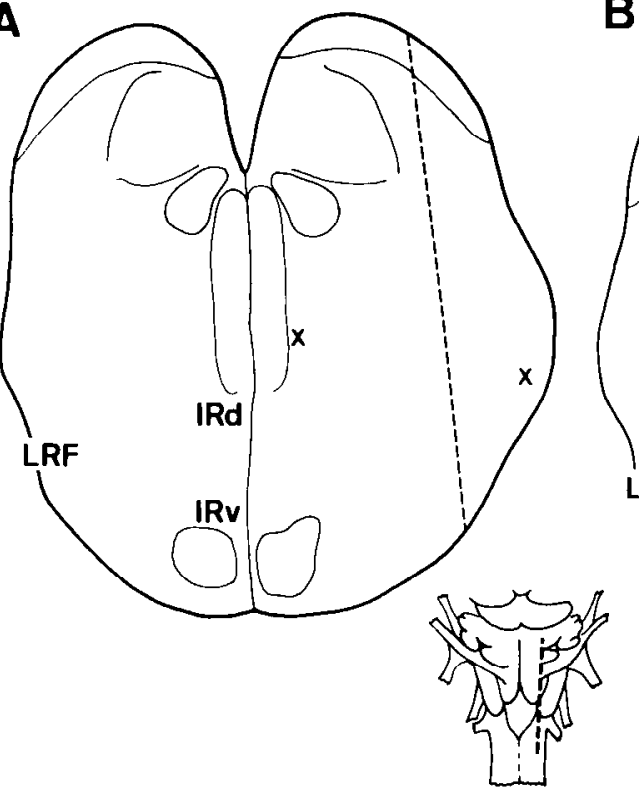

B

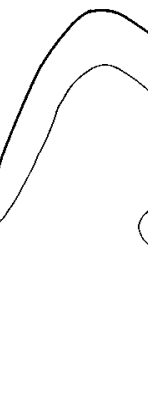

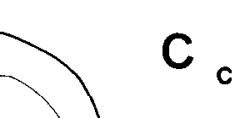

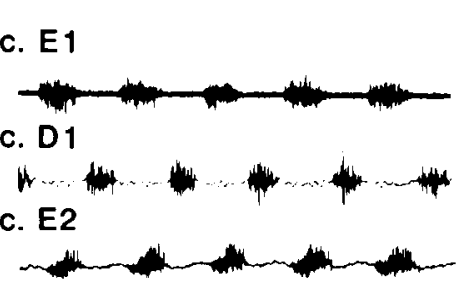

Figure 5. Effects of lesioning the brain stem and spinal cord on locomotion evoked from the lateral RF. A, Cross-sectional drawing of the brain stem with the location of a lesion (dotted line) separating the medial and lateral RF. Locomotion could be evoked by stimulation of the 2 sites marked by $X$ 's. The inset illustrates the rostrocaudal extent of the lesion in $A$ and $B . B, X$ marks a site from which locomotion could be evoked prior to lesioning of the spinal cord. The inset illustrates a lesion of the dorsolateral quadrant that was subsequently placed in the spinal cord. $C$, EMG record of swimming evoked by stimulation of the site marked in $B$, prior to lesioning of the spinal cord. $D$, EMG record of swimming evoked from the same site after lesioning of the dorsal quadrant of the spinal cord.

beled cells in the ipsilateral dorsal reticular nucleus (Livingston, 1987; C. A. Livingston, T. C. Ritchie, B. J. Williams, and R. B. Leonard, unpublished observations). The largest of these cells were labeled almost exclusively ipsilaterally and extended from approximately the rostral portion of the dorsal reticular nucleus through the middle RF. There was extensive overlap in the distribution of these cells and the locomotor sites responsive to chemical stimulation (Fig. 6). Reticulospinal cells in the rostral dorsal reticular nucleus and the middle RF are apparently the origin of the primary locomotor pathway in stingrays. These cells are located in the equivalent of the mammalian gigantocellular RF (Newman, 1985). Therefore, the primary pathway underlying locomotion in Dasyatis originates in the gigantocellular portion of the rhombencephalic RF, projects ipsilaterally into the ventral half of the lateral funiculus, and crosses the midline at segmental levels to evoke locomotion in the contralateral pectoral fin.

In monkeys, cats, and birds, as in Dasyatis, the primary locomotor pathway descends in the ventral half of the spinal cord (Steeves and Jordan, 1980; Eidelberg et al., 1981a, b; Kazennikov et al., 1984; Sholomenko and Steeves, 1987). The predominant source of reticulospinal fibers in these funiculi is the gigantocellular and magnocellular RF of the rostral medulla and caudal pons (Kuypers and Maisky, 1977; Tohyama et al., 1979; Cabot et al., 1982; Kuypers and Martin, 1982; Webster and Steeves, 1988). Locomotion in these species can be evoked by low-intensity electrical and chemical stimulation of these reticular areas (Orlovsky 1970a, b; Mori et al., 1978; Shefchyk et al., 1984; Armstrong, 1986; Garcia-Rill, 1986; Steeves et al., 1987; Noga et al., 1988). Evidence indicates, then, that the gigantocellular/magnocellular RF is the origin of the locomotor pathways descending from the caudal brain stem of monkeys, cats, and birds.
The locomotor pathway in turtles and in lampreys similarly originates in the magnocellular RF. Although Kazennikov et al. (1980) and ten Donkelaar (1982) reported that the locomotor strip in turtles is located in the lateral RF, it appears from their illustrations to be coextensive with the most lateral of the magnocellular reticulospinal cells (ten Donkelaar, 1976; Kazennikov et al., 1980). The locomotor strip in lampreys is also coincident with large reticulospinal cells (Rovainen, 1967, 1979; McClellan and Grillner, 1984).

In turtles, stimulation of the brain stem frequently evoked locomotion only in the contralateral limbs (Kazennikov et al., 1980), and stimulation in the spinal cord usually elicited locomotion in the contralateral limbs (Lennard and Stein, 1977; Stein, 1978). In these respects, descending locomotor control is similar in the turtle (ten Donkelaar, 1976) and Dasyatis. However, in cats, birds, and lampreys, evoked locomotion occurs bilaterally (McClellan and Grillner, 1984; Steeves et al., 1987; Noga et al., 1988). In rats, stimulation of the lateral portion of the pontine RF and the ventral reticular nucleus of the medulla evoked locomotion only in the contralateral limbs, whereas stimulation of the spinal trigeminal nucleus and the gigantocellular reticular nucleus evoked bilateral locomotion (Ross and Sinnamon, 1984). Interpretation of these differences among species requires further study.

Species-specific differences in the organization of brain stem locomotor control are evidenced by the extent of the RF involved in locomotion. In stingrays as well as in cats, rats, and birds, locomotion can be evoked electrically from a large portion of the rhombencephalic RF (Ross and Sinnamon, 1984; Steeves et al., 1987; Noga et al., 1988). In contrast, the effective region in turtles and lampreys extends over a long rostrocaudal distance, termed the "locomotor strip," but is restricted dorsoventrally and mediolaterally (Kazennikov et al., 1980; Mc- 
Clellan and Grillner, 1984). The extensive region from which locomotion can be evoked may be correlated with the increased development of the CNS in cats, rats, and birds, as in Dasyatis (an evolutionarily advanced elasmobranch; Northcutt, 1978), reflecting a requirement for the initiation system for locomotion to integrate input from numerous sources.

Previous studies demonstrated that the timing characteristics of swimming in the intact stingray were similar to those of spontaneous swimming in the decerebrate stingray (Leonard et al., 1979; Droge and Leonard, 1983b). Although only 1 fin was active, the timing characteristics of brain-stem-evoked swimming were similar to those of spontaneous swimming in intact or decerebrate stingrays. This contrasts with previous work in which electrical or pharmacological stimulation of the spinal cord in Dasyatis evoked swimming in which the timing characteristics were frequently altered (Williams et al., 1981, 1984).

\section{Effects of spinal cord and brain stem lesions on evoked locomotion}

The locomotor area in Dasyatis encompasses medial reticulospinal cells that project into the ventral half of the lateral funiculus and ventrolateral reticulospinal cells that project into the DLF (Livingston, 1987). To verify the relationship between the reticulospinal projections originating from these different regions and the 2 pathways previously identified in the spinal cord (Williams et al., 1984), we studied the interactive effects of spinal cord and brain stem lesions on brain-stem-evoked locomotion.

Lesions of the ventral quadrant of the spinal cord abolished or seriously impaired swimming evoked from the medial RF. This result would be predicted if locomotion wcre mediated by a direct reticulospinal projection from the gigantocellular RF into the ventral half of the spinal cord. However, it was not predicted that lesions of the ventral quadrant of the spinal cord would also abolish or impair locomotion evoked from the lateral RF. Further, we found that DLF lesions had no effect on locomotion evoked from the lateral RF.

There are 4 possible interpretations of these results. (1) Locomotion elicited from the lateral brain stem may be mediated by the direct reticulospinal projections into the DLF. (2) The lateral brain stem does not represent a separate and independent locomotor area, but mediates locomotion via the medial RF. (3) A pathway arising from the lateral RF acts in concert with the medial RF to evoke locomotion. (4) Locomotion elicited from the lateral RF is mediated by an indirect pathway involving other areas of the brain stem or rostral spinal cord (Orlovsky, 1970a; Budakova and Shik, 1980; Selionov and Shik, 1981).

1. If locomotion were mediated by direct reticulospinal projections from the lateral RF, then DLF lesions should have impaired swimming evoked from the lateral RF. Instead, DLF lesions had no effect on swimming evoked from the lateral RF, and in the absence of the ventral locomotor pathways, swimming evoked from the lateral brain stem was much weaker than normal. Similarly in cats, locomotion evoked by stimulation of the PLS is not abolished by bilateral lesions of the DLF, but it is abolished by lesions of the ventral quadrant (Kazennikov et al., 1984). Orlovsky (1970a) demonstrated in cats that stimulation of the PLS activated medial pontomedullary reticulospinal cells. If locomotion evoked from the lateral brain stem in stingrays involves a similar interaction between the medial and lateral RF, then ventral quadrant lesions would impair locomotion evoked from the lateral brain stem (Budakova and Shik, 1980; Selionov and Shik, 1981).

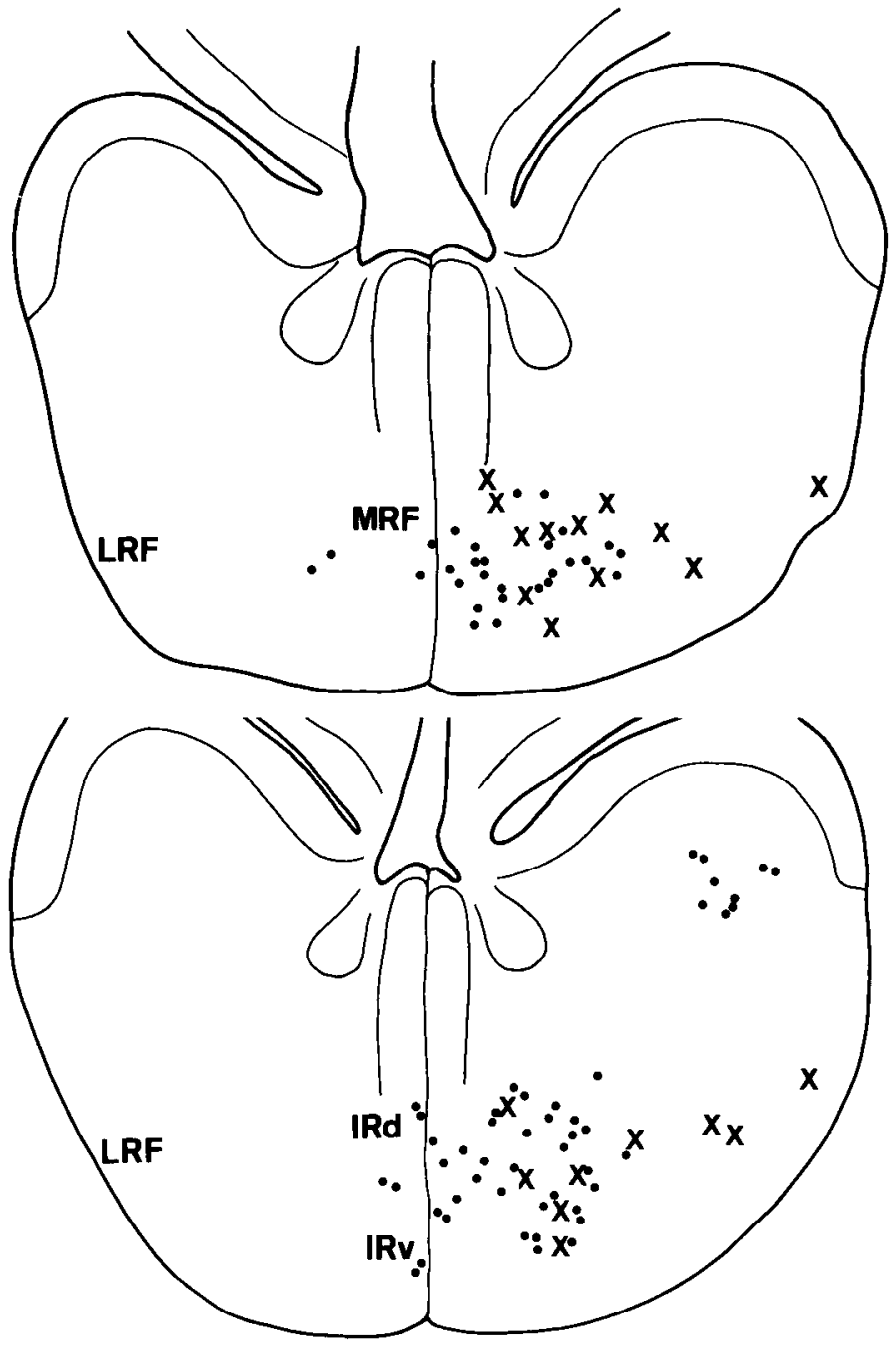

Figure 6. Cross-sectional drawing of the brain stem at the level of the gigantocellular RF, illustrating the coincident location of reticulospinal cells labeled by an HRP injection into the ventrolateral quadrant (filled circles) and the location of sites from which locomotion was evoked by chemical stimulation $\left(X^{\prime} \mathrm{s}\right)$. (The distribution of reticulospinal cells is taken from Livingston, 1987.)

2. Impairment of locomotion evoked from the lateral RF by ventral quadrant but not DLF lesions suggests that locomotion cannot be evoked from the lateral RF independently of the medial RF. To test this, the 2 regions were surgically isolated from each other. Locomotion could be evoked from the lateral sites after such lesions; therefore, locomotion evoked from the lateral RF is not exclusively dependent on an interaction with the medial RF.

3. Locomotion evoked from the lateral brain stem prior to lesioning may result from simultaneous activation of the medial and lateral RF. Activation of the medial reticulospinal cells could involve a synaptic relay (Orlovsky, 1970a) or be due to stimulation of their extensive dendritic projections into the lateral RF (Scheibel and Scheibel, 1958; Orlovsky, 1970a; Newman and Cruce, 1982; Smeets et al., 1983; Hlavacek et al., 1984; Newman, 1985).

4. To test whether locomotion evoked from the lateral RF is mediated by a pathway projecting indirectly to the spinal cord, we interrupted the DLF in animals in which the brain stem had been lesioned. Swimming could be evoked from sites lateral to 
the brain stem lesion in these animals. Because there is no significant projection of the lateral reticulospinal cells into the ventral half of the lateral funiculus (Livingston, 1987), swimming evoked from the lateral RF could not have been mediated via direct reticulospinal pathways. Therefore, the only pathway by which locomotion evoked from the lateral brain stem could be mediated is an indirect one involving either fibers projecting rostrally to structures above the brain stem lesion or reticulospinal cells located caudally near the spinomedullary junction. Because the brain stem lesion extended rostrally to near the level at which the brain stem was transected, a functional relay in this region is improbable. A more likely explanation would involve a relay with reticulospinal cells located in the caudalmost brain stem or neurons located in the rostral 1-2 segments of the spinal cord. In support of this, we had previously observed numerous cells located near the spinomedullary junction and in the rostral segments of the spinal cord in Dasyatis that projected caudally into the spinal cord (Livingston, 1987; C. A. Livingston, T. C. Ritchie, B. J. Williams, and R. B. Leonard, unpublished observations).

Earlier work suggests that the PLS, in the lateral brain stem of cats, comprises the axons of a column of interconnected propriobulbar neurons (Shik and Yagodnitsyn, 1977; Selionov and Shik, 1981; Kazennikov et al., 1983). Cells in spinal segments C2-C3, with descending axons 3-5 mm long, are monoand polysynaptically activated by stimulation of the PLS at intensities sufficient to evoke locomotion (Kazennikov et al., 1979). Thus, locomotion evoked from the PLS is mediated via an interconnected column of cells in the brain stem and spinal cord. Similarly, in Dasyatis the presence of isolated effective sites in the lateral RF after isolation from the medial RF and interruption of the DLF suggests that locomotion is mediated from the lateral brain stem via a relay onto neurons in the rostral spinal cord (Kazennikov et al., 1979; Roberts and Alford, 1986). This is in contrast to the suggestion of Armstrong (1986) that locomotion evoked from the PLS is mediated by direct reticulospinal projections into the DLF.

Noga et al. (1988) suggested that PLS-evoked locomotion in cats is mediated by cither descending or ascending fibers of the trigeminal sensory system (Matsushita et al., 1981). Our experiments did not address the possible involvement of ascending trigeminal afferents. However, in experiments in which both the brain stem and spinal cord were lesioned, our results do indicate that locomotion is not exclusively mediated by direct projections to the cervical spinal cord (Matsushita et al., 1981).

In experiments in which both the DLF and ventral quadrant of the spinal cord were lesioned or subsequent to hemisection of the spinal cord, isolated sites were found from which locomotion in the contralateral fin could be evoked. This suggests that although the locomotor pathway originates in the brain stem and descends into the ipsilateral ventral quadrant, pathways exist in the spinal cord that are capable, under certain conditions, of relaying the locomotor command to the pattern generator. These alternative pathways most likely are propriospinal, the role of which in the descending control of locomotion is poorly understood.

In conclusion, locomotion in the stingray is mediated by a pathway originating in the rhombencephalic RF that descends ipsilaterally in the ventral half of the lateral funiculus to elicit swimming in the contralateral pectoral fin. The results of electrical and chemical stimulation suggest that this pathway originates in the gigantocellular RF of the mid-rhombencephalon in
Dasyatis. We have also demonstrated that a pathway originating in the lateral RF can initiate locomotion independently of the medial RF. Our evidence suggests that this pathway mediates locomotion, not by direct reticulospinal projections, but indirectly via a relay through the medial $\mathrm{RF}$ or onto neurons located near the spinomedullary junction and/or in the rostral segments of the spinal cord.

The significance of each of the 2 pathways by which locomotion can be evoked in vertebrates is unknown. It is likely that both pathways are active during locomotion in the intact animal. Evidence suggests that the primary pathway, originating in the medial RF and descending into the ventral half of the spinal cord, is specifically associated with the initiation and control of locomotion. It has been suggested (Garcia-Rill and Skinner, 1987; Noga et al., 1988) that the pathway arising in the lateral RF is "nonspecific," integrating input from a variety of sources to initiate locomotion. Another function of the second pathway may be the coordination and gating of reflex and afferent activity in the spinal cord (Drew and Rossignol, 1984; Drew et al., 1986).

\section{References}

Armstrong, D. M. (1986) Supraspinal contributions to the initiation and control of locomotion in the cat. Prog. Neurobiol. 26: 274-361.

Bagshaw, E. V., and M. H. Evans (1976) Measurement of current spread from microelectrodes when stimulating within the nervous system. Exp. Brain Res. 25: 391-400.

Behbehani, M. M., and H. L. Fields (1979) Evidence that an excitatory connection between the periaqueductal gray and nucleus raphe magnus mediates stimulation produced analgesia. Brain Res. 170:85-93.

Budakova, N. N., and M. L. Shik (1980) Walking does not require continuity of the medullar locomotor strip. Bull. Exp. Biol. Med. USSR 89: 3-6.

Cabot, J. B., A. Reiner, and N. Bogan (1982) Avian bulbospinal pathways: Anterograde and retrograde studies of cells of origin, funicular trajectories and laminar terminations. In Descending Pathways to the Spinal Cord, Progress in Brain Research, Vol. 52, H. G. J. M. Kuypers and G. F. Martin, eds., pp. 79-108, Elsevier, Amsterdam.

Coggeshall, R. E., R. B. Leonard, M. L. Applebaum, and W. D. Willis (1978) Organization of the peripheral nerves and spinal roots of the Atlantic stingray, Dasyatis sabina. J. Neurophysiol. 41: 97-107.

Coles, S. K., J. F. Iles, and S. Nicolopoulos-Stournaras (1983) A mesencephalic locomotor centre in the rat. J. Physiol. (Lond.) 339: 14P.

Drew, T., and S. Rossignol (1984) Phase-dependent responses evoked in limb muscles by stimulation of medullary reticular formation during locomotion in thalamic cats. J. Neurophysiol. 52: 653-675.

Drew, T., R. Dubuc, and S. Rossignol (1986) Discharge patterns of reticulospinal and other reticular neurons in chronic, unrestrained cats walking on a treadmill. J. Neurophysiol. 55:375-401.

Droge, M. H., and R. B. Leonard (1983a) Swimming rhythm in decerebrated, paralyzed stingrays: Normal and abnormal coupling. J. Neurophysiol. 50: 178-191.

Droge, M. H., and R. B. Leonard (1983b) Swimming pattern in intact and decerebrated stingrays. J. Neurophysiol. 50: 162-177.

Eidelberg, E., J. L. Story, J. G. Walden, and B. L. Meyer (1981a) Anatomical correlates of return of locomotor function after partial spinal cord lesions in cats. Exp. Brain Res. 42: 81-88.

Eidelberg, E., J. G. Walden, and L. H. Nguyen (1981b) Locomotor control in macaque monkeys. Brain 104: 647-663.

Garcia-Rill, E. (1986) The basal ganglia and the locomotor regions. Brain Res. Rev. 11: 47-63.

Garcia-Rill, E., and R. D. Skinner (1987) The mesencephalic locomotor region. I. Activation of a medullary projection site. Brain Res. 411: $1-12$.

Garcia-Rill, E., R. D. Skinner, A. Gilmore, and R. Owings (1983) Connections of the mesencephalic locomotor region (MLR). II. Afferents and efferents. Brain Res. Bull. 10:63-71.

Garcia-Rill, E., R. D. Skinner, and J. A. Fitzgerald (1985) Chemical 
activation of the mesencephalic locomotor region. Brain Res. 330: 43-54.

Goodchild, A. K., R. A. L. Dampney, and R. Bandler (1982) A method for evoking physiological responses by stimulation of cell bodies, but not axons of passage, within localized regions of the central nervous system. J. Neurosci. Meth. 6: 351-363.

Grillner, S. (1975) Locomotion in vertebrates: Central mechanisms and reflex interactions. Physiol. Rev. 55: 274-304.

Grillner, S. (1981) Control of locomotion in bipeds, tetrapods, and fish. In Handbook of Physiology, Sect. 1, The Nervous System, Vol. II, Part 2, Motor Control, J. M. Brookhart, V. B. Mountcastle, V. B. Brooks, and S. R. Geiger, eds., pp. 1179-1236, American Physiological Society, Bethesda, MD.

Hlavacek, M., M. Tahar, S. Libouban, and T. Szabo (1984) The mormyrid brainstem. I. Distribution of brainstem neurones projecting to the spinal cord in Gnathonemus petersii. An HRP study. J. Hirnforsch. 25: 603-615.

Johnels, B., and G. Steg (1982) A mechanographic method for measurement of locomotor activity in rats. Effects of dopaminergic drugs and electric stimulation of the brainstem. J. Neurosci. Meth. 6:1727

Kashin, S., R. Brill, W. Ikehara, and A. Dizon (1981) Induced locomotion by midbrain stimulation in restrained skipjack tuna, Katsuwonus pelamis. J. Exp. Zool. 216: 327-329.

Kashin, S. M., A. G. Feldman, and G. N. Orlovsky (1974) Locomotion of fish evoked by electrical stimulation of the brain. Brain Res. 82: $41-47$.

Kazennikov, O. V., V. A. Selionov, M. L. Shik, and G. V. Yakovleva (1979) Neurons of upper cervical segments responding to stimulation of the bulbar locomotor strip. Neurophysiology (Kiev) 11: 179-185.

Kazennikov, O. V., V. A. Selionov, M. L. Shik, and G. V. Yakovleva (1980) The rhombencephalic "locomotor region" in turtles. Neirofiziologiya $12: 382-390$.

Kazennikov, O. V., M. L. Shik, and G. V. Yakovleva (1983) Stepping movements induced in cats by stimulation of the dorsolateral funiculus of the spinal cord. Bull. Exp. Biol. Med. USSR 96: 1036-1039.

Kazennikov, O. V., M. L. Shik, and G. V. Yakovleva (1984) Responses of upper cervical spinal neurons in cats to stimulation of the brain stem locomotor region at different frequencies. Neurophysiology 15 : 256-261.

Klüver, H., and E. Barrera (1953) A method for the combined staining of cells and fibres in the central nervous system. J. Neuropath. Exp. Neurol. 12: 400-403.

Kuypers, H. G. J. M., and V. A. Maisky (1977) Funicular trajectories of descending brain stem pathways in the cat. Brain Res. 136: 159165.

Kuypers, H. G. J. M., and G. F. Martin (1982) Descending Pathways to the Spinal Cord, Progress in Brain Research, Vol. 57, Elsevier, Amsterdam.

Lennard, P. R., and P. S. G. Stein (1977) Swimming movements elicited by electrical stimulation of turtle spinal cord. I. Low-spinal and intact preparations. J. Neurophysiol. 40: 768-778.

Leonard, R. B., P. Rudomin, M. H. Droge, A. E. Grossman, and W. D. Willis (1979) Locomotion in the decerebrate stingray. Neurosci. Lett. 14: 315-319.

Livingston, C. A. (1987) The Descending Pathways that Control Locomotion in the Atlantic stingray, Dasyatis sabina. Ph.D. Dissertation, University of Texas Medical Branch at Galveston.

Livingston, C. A., and R. B. Leonard (1986) Brainstem evoked locomotion in the Atlantic stingray, Dasyatis sabina. Soc. Neurosci. Abstr. 12: 387

Matsushita, M., N. Okado, M. Ikeda, and Y. Hosoya (1981) Descending projections from the spinal and mesencephalic nuclei of the trigeminal nerve to the spinal cord in the cat. A study with the horseradish peroxidase technique. J. Comp. Neurol. 196: 173-187.

McClellan, A. D., and S. Grillner (1984) Activation of "fictive swimming" by electrical microstimulation of brainstem locomotor regions in an in vitro preparation of the lamprey central nervous system. Brain Res. 300: 357-361.

Mori, S., M. L. Shik, and A. S. Yagodnitsyn (1977) Role of pontine tegmentum for locomotor control in mesencephalic cat. J. Neurophysiol. 40: 284-295.

Mori, S., H. Nishimura, C. Kurakami, T. Yamamura, and M. Aoki (1978) Controlled locomotion in the mesencephalic cat: Distribution of facilitatory and inhibitory regions within pontine tegmentum. $\mathrm{J}$ Neurophysiol. 41: 1580-1591.

Newman, D. B. (1985) Distinguishing rat brainstem reticulospinal nuclei by their neuronal morphology. I. Medullary nuclei. J. Hirnforsch. 26: 187-226

Newman, D. B., and W. L. R. Cruce (1982) The organization of the reptilian brainstem reticular formation: A comparative study using Nissl and Golgi techniques. J. Morphol. 173: 325-349.

Noga, B. R., J. Kettler, and L. M. Jordan (1988) Locomotion produced in mesencephalic cats by injections of putative transmitter substances and antagonists into the medial reticular formation and the pontomedullary locomotor strip. J. Neurosci. 8: 2074-2086.

Northcutt, R. G. (1978) Brain organization in the cartilaginous fishes. In Sensory Biology of Sharks, Skates and Rays, E. S. Hodgson and R. F. Mathewson, eds., pp. 117-194, U.S. Government Printing Office, Washington, DC.

Orlovsky, G. N. (1970a) Connexions of the reticulo-spinal neurones with the "locomotor sections" of the brain stem. Biophysics 15:178186

Orlovsky, G. N. (1970b) Work of the reticulo-spinal neurons during locomotion. Biofizika 15: 728-737.

Ranck, J. B., Jr. (1975) Which elements are excited in electrical stimulation of mammalian central nervous system: A review. Brain Res. 98: 417-440.

Roberts, A., and S. T. Alford (1986) Descending projections and excitation during fictive swimming in Xenopus embryos: Neuroanatomy and lesion experiments. J. Comp. Neurol. 250: 253-261.

Ross, G. S., and H. M. Sinnamon (1984) Forelimb and hindlimb stepping by the anesthetized rat elicited by electrical stimulation of the pons and medulla. Physiol. Behav. 33: 201-208.

Rovainen, C. M. (1967) Physiological and anatomical studies on large neurons of central nervous system of the sea lamprey (Petromyzon marinus). I. Muller and Mauthner cells. J. Neurophysiol. 38: 10001023.

Rovainen, C. M. (1979) Neurobiology of lampreys. Physiol. Rev. 59: 1007-1077.

Scheibel, M. E., and A. B. Scheibel (1958) Structural substrates for integrative patterns in the brainstem reticular core. In Reticular Formation of the Brain (Henry Ford Hosp. Symposium), H. H. Jasper, L. D. Proctor, R. S. Knighton, W. C. Noshay, and R. T. Costello, eds., pp. 31-55, Little, Brown, Boston.

Selionov, V. A., and M. L. Shik (1981) Response of medullary neurons to microstimulation of the locomotor strip in cat. Neurophysiol. (Kiev) 13: 275-282.

Shefchyk, S. J., R. M. Jell, and L. M. Jordan (1984) Reversible cooling of the brainstem reveals areas required for mesencephalic locomotor region evoked treadmill locomotion. Exp. Brain Res. 56: 257-262.

Shik, M. L., and A. S. Yagodnitsyn (1977) The pontobulbar "locomotor strip." Neurophysiology (Kiev) 9: 72-74.

Shik, M. L., and A. S. Yagodnitsyn (1978) Unit responses in the "locomotor strip" of the cat hindbrain to microstimulation. Neurophysiology (Kiev) 10: 373-379.

Shik, M. L., F. V. Severin, and G. N. Orlovsky (1966) Control of walking by means of electrical stimulation of the midbrain. Biophysics 11: 756-765.

Shimamura, M., and I. Kogure (1983) Discharge patterns of reticulospinal neurons corresponding with quadrupedal leg movements in thalamic cats. Brain Res. 230: 27-34.

Sholomenko, G. N., and J. D. Steeves (1987) Effects of selective spinal cord lesions on hind limb locomotion in birds. Exp. Neurol. 95: 403418 .

Smeets, W. J. A. J., R. Nieuwenhuys, and B. L. Roberts (1983) The Central Nervous System of Cartilaginous Fishes, Springer-Verlag, Berlin.

Steeves, J. D., and L. M. Jordan (1980) Localization of a descending pathway in the spinal cord which is necessary for controlled treadmill locomotion. Neurosci. Lett. 20: 283-288.

Steeves, J. D. and L. M. Jordan (1984) Autoradiographic demonstration of the projections from the mesencephalic locomotor region. Brain Res. 307: 263-276.

Steeves, J. D., G. N. Sholomenko, and D. M. S. Webster (1987) Stimulation of the pontomedullary reticular formation initiates locomotion in decerebrate birds. Brain Res. 401: 205-212.

Stein, P. S. G. (1978) Swimming movements elicited by clectrical 
stimulation of the turtle spinal cord: The high spinal preparation. $\mathrm{J}$ Comp. Neurol. 124: 203-210.

ten Donkelaar, H. J. (1976) Descending pathways from the brain stem to the spinal cord in some reptiles. I. Origin. J. Comp. Neurol. 167: $421-442$.

ten Donkelaar, H. J. (1982) Organization of descending pathways to the spinal cord in amphibians and reptiles. In Descending Pathways to the Spinal Cord, Progress in Brain Research, Vol. 57, H. G. J. M. Kuypers and G. F. Martin, eds., pp. 25-68, Elsevier, Amsterdam.

Tohyama, M., K. Sakai, D. Salvert, M. Touret, and M. Jouvet (1979) Spinal projections from the lower brain stem in the cat as demonstrated by the horseradish peroxidase technique. I. Origins of the reticulospinal tracts and their funicular trajectories. Brain Res. 173: 383-403.

Webster, D. M. S., and J. D. Steeves (1988) Origins of brainstem- spinal projections in the duck and goose. J. Comp. Neurol. 273: 573583.

Williams, B. J., M. H. Droge, K. Hester, and R. B. Leonard (1981) Induction of swimming in the high spinal stingray by L-DOPA. Brain Res. 220: 208-213.

Williams, B. J., C. A. Livingston, and R. B. Leonard (1984) Spinal cord pathways involved in initiation of swimming in the stingray, Dasyatis sahina: Spinal cord stimulation and lesions. J. Neurophysiol. 51: 578-591.

Wise, R. A. (1972) Spread of current from monopolar stimulation of the lateral hypothalamus. Am. J. Physiol. 223: 545-548.

Zemlan, F. P., L. M. Kow, and D. W. Pfaff (1983) Effect of interruption of bulbospinal pathways on lordosis, posture and locomotion. Exp. Neurol. 81: 177-194. 